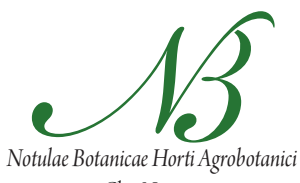

Clij-Napoca

\title{
Improvement of Root System Architecture in Peach (Prunus persica) Seedlings by Arbuscular Mycorrhizal Fungi, Related to Allocation of Glucose/Sucrose to Root
}

\author{
Qiang-Sheng WU'*, Guo-Huai LI², Ying-Ning ZOU' \\ ${ }^{1}$ Yangtze University, College of Horticulture and Gardening, 88 Jingmi Road, Jingzhou, Hubei \\ 434025, People's Republic of China; wuqiangsh@163.com ("corresponding author) \\ ${ }^{2}$ Huazhong Agricultural University, Key Laboratory of Horticultural Plant Biology, Ministry \\ of Education, Wuban, Hubei 430070, People's Republic of China
}

\begin{abstract}
Root system architecture (RSA) is used to describe the spatial configuration of a root system in the soil, which substantially determines the capacity of a plant to take up nutrients and water. The present study was to assess if arbuscular mycorrhizal fungi (AMF), Glomus mosseae, G. versiforme, and Paraglomus occultum would alter RSA of peach (Prunus persica L. Batsch) seedlings, and the alteration due to mycorrhization was related to allocation of glucose/sucrose to root $\left(\mathrm{A}_{\text {slucose/sucrose }}\right)$. Inoculation with G. mosseae and G. versiforme significantly increased leaf, stem, root and total fresh weights, compared with non-AMF treatment. Mycorrhizal alterations of RSA in peach plants were dependent on AMF species, because only $G$. mosseae and G. versiforme but not $P$. occultum markedly increased root length, root projected area, root surface area and root volume. For the distribution of root length classes, AMF mainly increased 0-1 and 3-4 cm root length classes, which is AMF species dependent. Inoculated seedlings with Glomus species recorded significantly higher root sucrose and leaf and root glucose concentrations and lower root sucrose concentrations than un-inoculated control. Compared with the non-AMF treatment, $G$. mosseae and $G$. versiforme generally increased the $\mathrm{A}_{\text {glucose }}$ and $\mathrm{A}_{\text {sucrose }}$, but $P$. occultum significantly decreased the $\mathrm{A}_{\text {glucose }}$ and $\mathrm{A}_{\text {sucrose }}$. $\mathrm{A}_{\text {sucrose }}$ or $\mathrm{A}_{\text {glucose }}$ was significantly positive correlated with root length, root projected area and root surface area. The results suggest that AMF modified variables of RSA in peach, which is AMF species dependent and related to $A_{\text {glucose }}$ and $A_{\text {su }}$
\end{abstract}

Keywords: allocation of carbohydrate to root, arbuscular mycorrhiza, Glomus, glucose, root length class, root system architecture, sucrose

\section{Introduction}

Plant roots play an important role in plant growth, development and fitness (Zhu et al., 2011). Generally, roots can provide anchorage and support for the shoot, uptake water and nutrients, store carbohydrates, take part in the biosynthesis of important hormones, and are involved in interactions with the rhizosphere. In roots, root system architecture (RSA) is the spatial configuration of a root system in the soil, which substantially determines the ability of a plant to secure edaphic resources (de Dorlodot et al., 2007). So, alteration of RSA will profoundly affect the capacity of plants to uptake water and nutrients. Except for genetic factor, environmental factors such as water, nitrate, phosphate, and rhizospheric microorganisms strongly influence RSA of plant (Ingram and Malamy, 2010).

Arbuscular mycorrhizal fungi (AMF) are obligate biotrophs and can form mutualistic association with roots of higher plants, which involves the transfer of mineral nutrients and water from AMF to host plant in exchange for carbon (Bainard et al., 2011). Inoculation with Glomus intraradices significantly led to increase the formation of lateral roots in rice (Oryza sative) plant (Gutjahr et al.,
2009). In red tangerine (Citrus tangerine) seedlings, $G$. mosseae notably improved parameters of RSA, including total root length, total root projected area, total root surface and total root volume and decreased root average diameter significantly, compared with the non-AMF control (Wu et al., 2010). However, there are also data suggesting that AMF either did not change or reduced RSA of host plants (Forbes et al., 1996; Trotta et al., 1996). There is evidence to suggest that RSA modifications due to AMF are independent of common symbiosis signaling (Gutjahr et al., 2009) and a consequence of changed nutrition (Fitter and Stickland, 1991). RSA modifications are regulated by external and internal physiological status (Gahoonia et al., 2007; Tolsma et al., 2007), and other mechanisms including carbohydrate allocation are involved too.

Peach is a delicious fruit with lots of nutrition values and is widely distributed and cultivated all around the world, including China. Although mycorrhizal symbiosis could help peach seedlings to overcome soil-fumigation nutrient-deficiency effects in nursery and alleviate flooded stress, but not overcome peach replant problem (Rutto et al, 2002; Rutto and Mizutani, 2006), there is no information about the role of AMF on RSA of peach. Here, it has 
been determined the AMF effect on RSA of peach, which is related to carbohydrate allocation.

\section{Materials and methods}

\section{Experimental design}

The experiment was arranged in a completely random design with four AMF treatments (G. mosseae, G. versiforme, Paraglomus occultum and non-AMF control), each with 4 replicates for a total of 16 pots (one seedling per pot).

\section{Plant culture}

Sixteen uniform-size peach (Prunus persica L. Batsch) seedlings with 9 10 leaves after sand stratification and germination in sand bed were selected as the experimental materials and respectively transferred into a plastic pot $(18.5 \mathrm{~cm}$ upper mouth diameter $\times 9.5 \mathrm{~cm}$ bottom mouth diameter $\times 11.5 \mathrm{~cm}$ height) containing $2.7 \mathrm{~kg}$ of autoclaved $\left(121^{\circ} \mathrm{C}, 0.11 \mathrm{MPa}, 1 \mathrm{~h}\right)$ soil/vermiculite/sphagnum $(5: 1: 1, \mathrm{v} / \mathrm{v} / \mathrm{v})$ growth substrates, whose characteristics were $\mathrm{pH} 6.3,0.98 \%$ organic matter, and $17.71 \mathrm{mg}$ $\mathrm{kg}^{-1}$ available phosphorus. The pot growth substrates had been previously inoculated with the G. mosseae, G. versiforme and P. occultum before transplanting by placing $25 \mathrm{~g}$ of mycorrhizal inocula in the rhizosphere. The non-AMF control received an equal amount of autoclaved inocula with a $2 \mathrm{ml}$ aliquot of a filtrate of mycorrhizal inocula to provide a general microbial population free of mycorrhizal propagules. These mycorrhizal inocula contained spores, external hyphae and mycorrhizal root fragments from Sorghum vulgare, which were commercially provided by the Institute of Plant Nutrition and Resources, Beijing Academy of Agriculture and Forestry Sciences.

The experiment was arranged in a non-environmentally controlled plastic greenhouse from April 1 to July 21, 2010, where photo flux density is $600 \sim 900 \mu \mathrm{mol} \mathrm{m}^{-2} \mathrm{~s}^{-1}$, average day/night temperature $24.6 / 16.7^{\circ} \mathrm{C}$, and relative humidity $70-95 \%$, respectively.

\section{Parameter analysis}

After 16 weeks of mycorrhizal inoculations, plants were separated carefully from the pots by gently washing off these substrates adhering to the roots, and leaf, stem and root fresh weights were recorded.

The intact root systems were scanned with an Epson Expression/STD 4800 Scanner and analyzed with the WinRHIZO Pro 2007b software (Regent Instruments Inc., Quebec, Canada).

Root mycorrhizal colonization was determined by examining $0.05 \%$ trypan blue-stained fine roots (Phillips and Hayman, 1970) and expressed as percentage root length infected (Wu and Zou, 2009). Mycorrhizal dependency was determined by expressing the fresh weight of mycorrhizal plant as a percentage of the fresh weight of a non-mycorrhizal plant (Menge et al., 1978).
Extracts for the determinations of glucose and sucrose were followed by Wu et al. (2010). Glucose and sucrose concentrations were determined by the methods of Zhang and Zai (2004). Allocation of glucose/sucrose to root $\left(\mathrm{A}_{\text {glucose/sucrose }}\right)$ was quantified based on the formula (Wu $e t$ al., 2010):

$$
\mathrm{A}_{\text {glucose/sucrose }}(\%)=\frac{\mathrm{S}_{\text {root }}}{S_{\text {leaf }}+S_{\text {root }}} \times 100
$$

Where $S_{\text {leaf }}$ and $S_{\text {root }}$ are the values of glucose/sucrose concentration in leaf and root, respectively.

\section{Statistical analysis}

Data $(n=4)$ were analyzed by one-factor ANOVA with SAS version 8.1 software. Differences in means were compared by Fisher's Protected Least Significant Difference (LSD) and considered significant at $P<0.05$. Pearson correlation coefficients between $\mathrm{A}_{\text {glucose/sucrose }}$ and RSA variables were calculated using the Proc Corr procedure in SAS (v8.1).

\section{Results and discussion}

\section{Mycorrbizal colonization}

In the present work, there was no mycorrhizal colonization in the non-AMF control peach seedlings. Mycorrhizal colonization of the inoculated seedlings ranged from 23.4 to $54.9 \%$ (Fig. 1). Root colonization of the peach seedlings was significantly highest with $G$. mosseae, greater with G. versiforme and least with $P$. occultum (Fig. 1 ), suggesting that mycorrhizal colonization in the root of peach seedlings might be AMF species dependent.

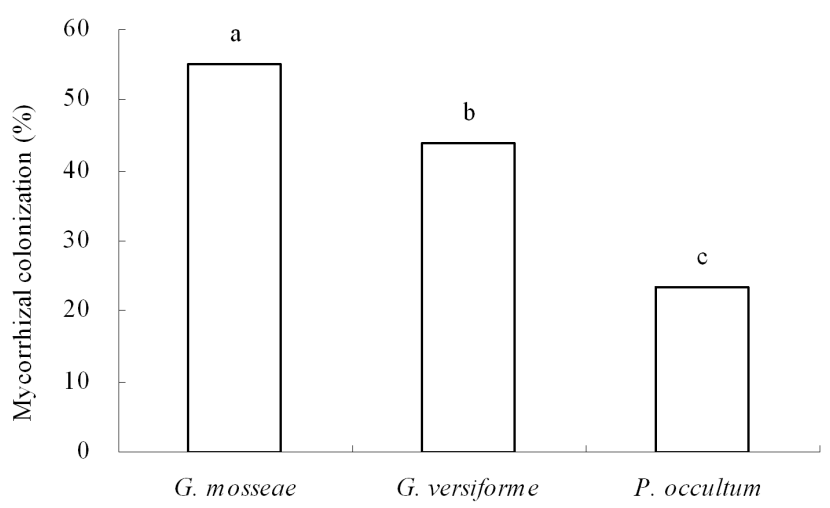

Fig. 1. Mycorrhizal colonization of peach (Prunus persica) seedlings inoculated with G. mosseae, G. versiforme and $P$. occultum. Data followed by the same letter above the bars are not significantly different among treatments at $P<0.05$ (LSD test)

\section{Plant growth}

AMF generally increases plant growth, and thus AM colonization is important in plant growth (Smith and Read, 2008). In the study, inoculation with G. mosseae and $G$.versiforme but not with $P$. occultum significantly increased leaf, stem, root and total fresh weights, compared with the non-AMF control (Fig. 2; Tab. 1). The result sug- 
Tab. 1. Effects of AMF on plant growth and mycorrhizal dependency of peach (Prunus persica L. Batsch) seedlings

\begin{tabular}{cccccc}
\hline $\begin{array}{c}\text { Mycorrhizal } \\
\text { inoculation }\end{array}$ & $\begin{array}{c}\text { Leaf fresh weight } \\
(\mathrm{g} / \mathrm{plant})\end{array}$ & $\begin{array}{c}\text { Stem fresh weight } \\
\text { (g/plant) }\end{array}$ & $\begin{array}{c}\text { Root fresh weight } \\
(\mathrm{g} / \mathrm{plant})\end{array}$ & $\begin{array}{c}\text { Total plant fresh } \\
\text { weight }(\mathrm{g} / \mathrm{plant})\end{array}$ & $\begin{array}{c}\text { Mycorrhizal dependency } \\
(\%)\end{array}$ \\
\hline G. mosseae & $4.40 \mathrm{a}$ & $3.46 \mathrm{a}$ & $4.98 \mathrm{a}$ & $12.84 \mathrm{a}$ & 136.89 \\
G. versiforme & $3.38 \mathrm{~b}$ & $3.22 \mathrm{ab}$ & $3.80 \mathrm{~b}$ & $10.80 \mathrm{~b}$ & 115.14 \\
P. occultum & $3.27 \mathrm{c}$ & $2.96 \mathrm{bc}$ & $3.73 \mathrm{bc}$ & $9.96 \mathrm{bc}$ & 106.18 \\
Non-AMF & $3.28 \mathrm{c}$ & $2.82 \mathrm{c}$ & $3.28 \mathrm{c}$ & $9.38 \mathrm{c}$ & - \\
\hline
\end{tabular}

Data followed by the same letter within a column indicate no significant difference among treatments at $P<0.05$ (LSD test)

Tab. 2. Effects of AMF on RSA variables of peach (Prunus persica L. Batsch) seedlings

\begin{tabular}{cccccc}
\hline $\begin{array}{c}\text { Mycorrhizal } \\
\text { inoculation }\end{array}$ & $\begin{array}{c}\text { Average diameter } \\
(\mathrm{mm})\end{array}$ & $\begin{array}{c}\text { Length } \\
(\mathrm{cm})\end{array}$ & $\begin{array}{c}\text { Projected area } \\
\left(\mathrm{cm}^{2}\right)\end{array}$ & $\begin{array}{c}\text { Surface area } \\
\left(\mathrm{cm}^{2}\right)\end{array}$ & $\begin{array}{c}\text { Volume } \\
\left(\mathrm{cm}^{3}\right)\end{array}$ \\
\hline G. mosseae & $0.44 \mathrm{a}$ & $951.77 \mathrm{a}$ & $41.47 \mathrm{a}$ & $130.29 \mathrm{a}$ & $1.42 \mathrm{a}$ \\
\hline G.versiforme & $0.40 \mathrm{a}$ & $960.43 \mathrm{a}$ & $38.48 \mathrm{a}$ & $120.89 \mathrm{a}$ & $1.22 \mathrm{ab}$ \\
P. occultum & $0.43 \mathrm{a}$ & $765.86 \mathrm{~b}$ & $32.77 \mathrm{~b}$ & $102.94 \mathrm{~b}$ & $1.11 \mathrm{bc}$ \\
\hline Non-AMF & $0.39 \mathrm{a}$ & $779.33 \mathrm{~b}$ & $30.09 \mathrm{~b}$ & $94.53 \mathrm{~b}$ & $0.92 \mathrm{c}$ \\
\hline
\end{tabular}

Data followed by the same letter within a column indicate no significant difference among treatments at $P<0.05$ (LSD test)

gests the different efficiencies of AMF species on increasing peach growth. Previous studies have also reported dramatic differences in citrus and Prunus rootstocks growth as a function of difference AMF isolates, which are due to both P limitation and high C costs (Calvet et al., 2004; Fidelibus et al., 2000).

Additionally, mycorrhizal dependency of peach seedlings for the three AMF was as follows: G. mosseae $>G$. versiforme $>$ P. occultum (Tab. 2). This indicates that AMF species might alter mycorrhizal dependency of peach seedlings, although certain nutrients such as N, P, Zn, Fe and $\mathrm{Ca}$ and root hair length or density of host plant could alter mycorrhizal dependency (Azcón and Ocampo, 1981; Collier et al., 2003; Declerck et al., 1995; Seifert et al., 2009).

\section{Root system architecture (RSA)}

Compared with the non-AMF control, the present results showed that AMF could alter RSA of peach seedlings. In the three AMF used here, only G. mosseae and $G$. versiforme significantly increased root length, root pro-

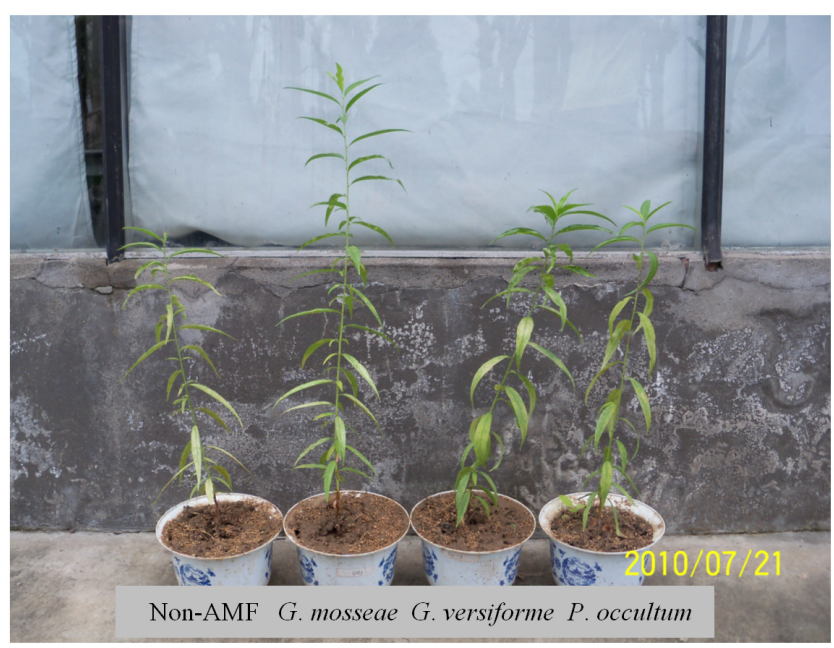

Fig. 2. Plant growth status of AMF and non-AMF peach (Prunuspersica) seedlings jected area, root surface area and root volume (Tab. 2). Such results in peach seedlings are consistent with those in grapevine and red tangerine (Augín et al., 2004; Wu et al., 2010). Inoculation with P. occultum did not alter the parameters of RSA in peach seedlings (Tab. 2), which is in agreement with no mycorrhizal effect on RSA of tomato (Lycopersicum esculentum) plants colonized by G. mosseae (Trotta et al., 1996). These results suggest that RSA modifications are dependent on AMF species.

For the distribution of root length classes, the present results clearly showed that peach seedlings depended on $0-1 \mathrm{~cm}$ root length class in the entire root system from 93.15 to $95.02 \%$ (Tab.3). Compared to the non-AMF control, G. mosseae significantly increased 0-1 cm root length class by $19.98 \%, 3-4 \mathrm{~cm}$ root length class by $347.83 \%$ and $>4 \mathrm{~cm}$ root length class by $81.34 \%$ (Tab. 3). Significantly higher $0-1 \mathrm{~cm}$ root length class $(22.50 \%)$ in G. versiformecolonized seedlings and $3-4 \mathrm{~cm}$ root length class (233.33292.75\%) in G. versiforme- or P. occultum-colonized seedlings were observed, compared to the non-AMF seedlings. The results imply that AMF seems to induce initiation of higher lateral root. Other studies showed that branching of primary, secondary and tertiary roots in Vitis vinifera colonized by $G$. fasciculatum was $140 \%, 200 \%$ and $266 \%$ respectively greater than non-AMF roots (Schellenbaum et al., 1991).

\section{Carbohydrates}

In the present study, AMF colonization obviously altered sucrose and glucose concentrations in leaves and roots of peach seedlings (Fig. 3). In general, the seedlings infected with $G$. mosseae and G. versiforme recorded higher root sucrose concentrations, leaf and root glucose concentrations and lower leaf sucrose concentrations, and $P$. occultum increased leaf glucose and sucrose concentration, decreased root sucrose concentrations, and did not alter root glucose concentrations (Fig. 3). AM symbiosis must obtain $4-20 \%$ of the plant's total carbon budget for sustaining itself development (Wu et al., 2010). Herein, 
Tab. 3. Effect of AMF on the distribution of root length classes of peach (Prunus persica L. Batsch) seedlings

\begin{tabular}{cccccc}
\hline Mycorrhizal & \multicolumn{5}{c}{ Root length classes $(\mathrm{cm})$} \\
\cline { 2 - 6 } inoculation & $0-1 \mathrm{~cm}$ & $1-2 \mathrm{~cm}$ & $2-3 \mathrm{~cm}$ & $3-4 \mathrm{~cm}$ & $>4 \mathrm{~cm}$ \\
\hline G. mosseae & $888.62 \mathrm{a}$ & $39.58 \mathrm{a}$ & $8.61 \mathrm{a}$ & $3.09 \mathrm{a}$ & $10.30 \mathrm{a}$ \\
G. versiforme & $907.30 \mathrm{a}$ & $35.33 \mathrm{a}$ & $7.71 \mathrm{a}$ & $2.30 \mathrm{a}$ & $6.20 \mathrm{~b}$ \\
P. occultum & $714.00 \mathrm{~b}$ & $34.08 \mathrm{a}$ & $6.59 \mathrm{a}$ & $2.71 \mathrm{a}$ & $7.17 \mathrm{~b}$ \\
Non-AMF & $740.67 \mathrm{~b}$ & $26.68 \mathrm{a}$ & $4.12 \mathrm{a}$ & $0.69 \mathrm{~b}$ & $5.68 \mathrm{~b}$ \\
\hline
\end{tabular}

Note: Data followed by the same letter within a column indicate no significant difference among treatments at $P<0.05$ (LSD test)
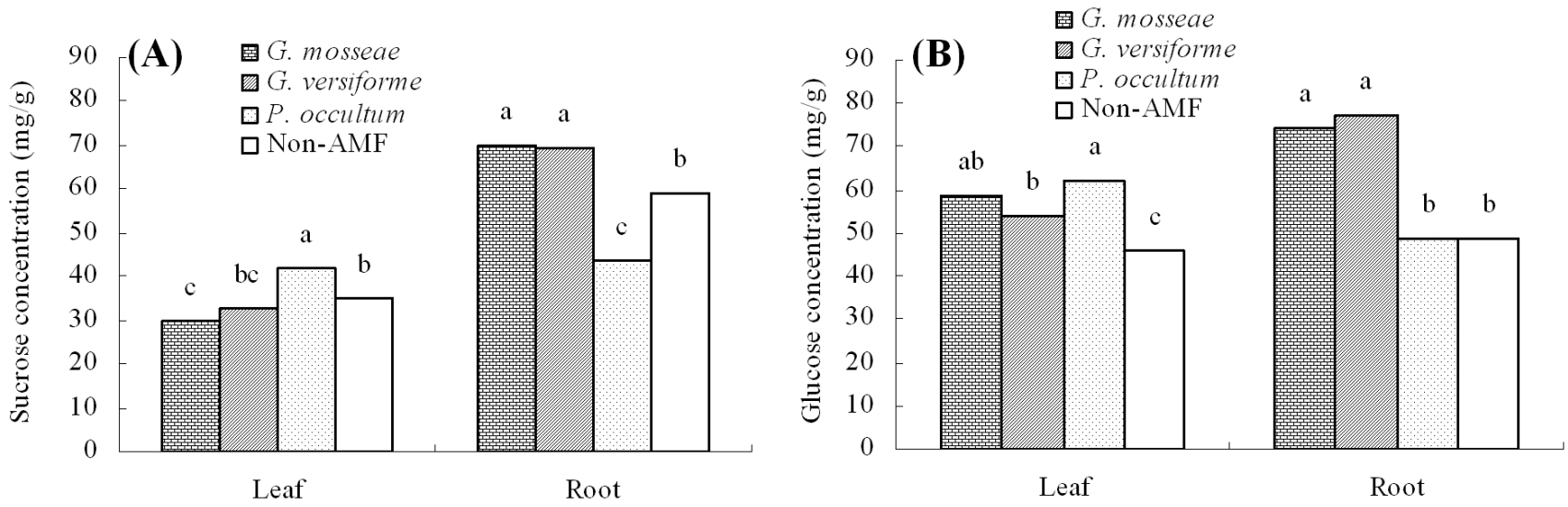

Fig. 3. Effect of AMF on sucrose (A) and glucose (B) concentration of peach (Prunus persica) seedlings. Data followed by the same letter above the bars are not significantly different among treatments at $P<0.05$ (LSD test)

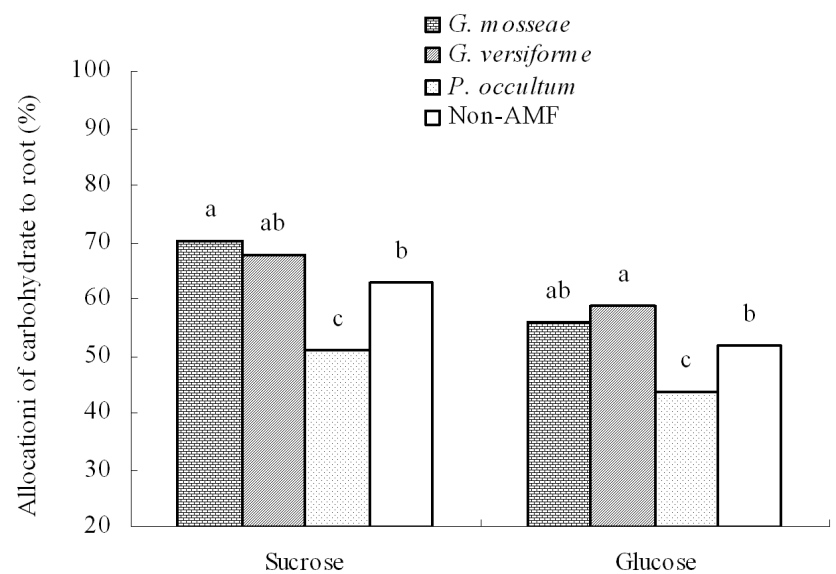

Fig. 4. Effect of AMF on allocation of sucrose/glucose to root of peach (Prunus persica) seedlings. Data followed by the same letter above the bars are not significantly different among treatments at $P<0.05$ (LSD test)

AM symbiosis acquires hexose, which is transformed into trehalose and glycogen in AM. A significantly positive correlation $(r=0.800, P<0.01)$ between allocation of sucrose to root and allocation of glucose to root was observed in the seedlings, implying that the mycorrhizal presence can alter the carbohydrate transformation. Therefore, a higher concentration of glucose (a form of hexose) occurred in leaves and roots of $G$. mosseae-and $G$.versiforme-colonized seedlings would help host plants to establish better mycorrhizal development. The result is in agreement with a previous study by Wu et al. (2010), who reported the increments of glucose concentrations in red tangerine (Citrus tangerine) colonized by G. mosseae.

Data presented in Fig. 4 showed that compared with the non-AMF treatment, $G$. mosseae and $G$. versiforme generally increased the $\mathrm{A}_{\text {glucose }}$ and/or $\mathrm{A}_{\text {sucrose }}$, but $P$. occultum significantly decreased the $\mathrm{A}_{\text {glucose }}$ by $15.10 \%$ and the $\mathrm{A}_{\text {sucrose }}$ by $18.58 \%$, suggesting that mycorrhizal symbiosis influences the allocation of photosynthetically fixed carbon to root. Since the similarly changed trend was also in parameter modification of RSA by mycorrhization (Tab. $2), A_{\text {sucrose }}$ or $A_{\text {glucose }}$ was significantly positive correlated with root length $(P<0.01)$, root projected area $(P<0.05)$ and root surface area $(P<0.05)$ (Tab. 4$)$. Roots are recognized as metabolic sinks (Robbins and Pharr, 1988). Root growth is closed related to carbon import, and the major loss of root carbon occurs via root respiration (Walter and Nagel, 2006). Therefore, it is reasonable to believe that modification of RSA due to mycorrhization was related to the corresponding alteration of $\mathrm{A}_{\text {glucose }}$ and/or $\mathrm{A}_{\text {sucrose }}$.

Tab. 4. Pearson correlation coefficients between $A_{\text {glucose/sucrose }}$ and RSA variables $(n=16)$

\begin{tabular}{cccccc}
\hline & $\begin{array}{c}\text { Root average diameter } \\
(\mathrm{mm})\end{array}$ & $\begin{array}{c}\text { Root length } \\
(\mathrm{cm})\end{array}$ & $\begin{array}{c}\text { Root projected area } \\
\left(\mathrm{cm}^{2}\right)\end{array}$ & $\begin{array}{c}\text { Root surface area } \\
\left(\mathrm{cm}^{2}\right)\end{array}$ & $\begin{array}{c}\text { Root volume } \\
\left(\mathrm{cm}^{3}\right)\end{array}$ \\
\hline $\mathrm{A}_{\text {sucrose }}(\%)$ & -0.059 & $0.687^{* *}$ & $0.585^{*}$ & $0.585^{*}$ & 0.439 \\
$\mathrm{~A}_{\text {glucose }}(\%)$ & -0.131 & $0.716^{* *}$ & $0.579^{*}$ & $0.579^{*}$ & 0.416 \\
\hline
\end{tabular}

${ }^{*} P<0.05 .{ }^{* *} P<0.01$ 


\section{Conclusions}

In conclusion, the present results demonstrated that $G$. mosseae and G. versiforme but not $P$. occultum significantly improved traits of RSA in peach seedlings, which is AMF species dependent. The AMF-induced alterations of sucrose and glucose concentrations and $\mathrm{A}_{\text {glucose }}$ and $\mathrm{A}_{\text {sucrose }}$ might be related to AMF demand for sustaining symbiosis development and to the improvement of RSA for maintaining root respiratory and growth processes.

\section{Acknowledgements}

This work was supported by the Earmarked Fund for Modern Agro-industry Technology Research System (CARS-31-2-4).

\section{References}

Augín O, Mansilla JP, Vilariño A, Sainz M (2004). Effects of mycorrhizal inoculation on root morphology and nursery production of three grapevine rootstocks. Am J Enol Vitic 55:108-111.

Azcón R, Ocampo JA (1981). Factors affecting the vesiculararbuscular infection and mycorrhizal dependency of thirteen wheat cultivars. New Phytol 87:677-685.

Bainard LD, Klironomos JN, Gordon AM (2011). Arbuscular mycorrhizal fungi in tree-based intercropping systems: a review of their abundance and diversity. Pedobiologia 54:57-61.

Calvet C, Estaun V, Camprubi A, Hernandez-Dorrego A, Pinochet J, Moreno MA (2004). Aptitude for mycorrhizal root colonization in Prunus rootstocks. Sci Hort 100:39-49.

Collier SC, Yarnes CT, Herman RP (2003). Mycorrhizal dependency of Chihuahuan Desert plants is influenced by life history strategy and root morphology. J Arid Environ 55:223-229.

de Dorlodot S, Forster B, Pages L, Price A, Tuberosa R, Draye $X$ (2007). Root system architecture: opportunities and constraints for genetic improvement of crops. Trends Plant Sci 12:474-481.

Declerck S, Plenchette C, Strullu DG (1995). Mycorrhizal dependency of banana (Musa acuminata, AAA group) cultivar. Plant Soil 176:183-187.

Fidelibus MW, Martin CA, Wright GC, Stutz JC (2000). Effect of arbuscular mycorrhizal (AM) fungal communities on growth of 'Volkamer' lemon in continually moist or periodically dry soil. Sci Hort 84:127-140.

Fitter AH, Stickland TR (1991). Architecture analysis of plant root systems. 2. Influence of nutrient supply on architecture in contrasting plant species. New Phytol 118:383-389.

Forbes PJ, Ellison CH, Hooker JE (1996). The impact of arbuscular mycorrhizal fungi and temperatur on root system development. Agron 16:617-620.

Gahoonia TS, Ali R, Malhotra RS, Jahoor A, Rahman MM (2007). Variation in root morphological and physiological traits and nutrient uptake of chickpea genotypes. J Plant Nutri 30:829-41.
Gutjahr C, Casieri L, Paszkowski U (2009). Glomus intraradices induces changes in root system architecture of rice independently of common symbiosis signaling. New Phytol 182:829-837

Ingram PA, Malamy JE (2010). Root system architecture. Adv Bot Res 55:75-117.

Menge JA, Johnson ELV, Platt RG (1978). Mycorrhizal dependency of several citrus cultivars under three nutrient regimes. New Phytol 81:553-559.

Phillips JM, Hayman DS (1970). Improved procedures for clearing roots and staining parasitic and vesicular-arbusular mycorrhizal fungi for rapid assessment of infection. Trans $\mathrm{Br}$ Mycol Soc 55:158-161.

Robbins NS, Pharr DM (1988). Effect of restricted root growth on carbohydrate metabolism and whole plant growth of Cucumis sativus L. Plant Physiol 87:409-413.

Rutto KL, Mizutani F (2006). Peach seedlings growth in replant and non-replant soils after inoculation with arbuscular mycorrhizal fungi. Soil Biol Biochem 38:2536-2542.

Rutto KL, Mizutani F, Kadoya K (2002). Effect of root-zone flooding on mycorrhizal and non-mycorrhizal peach (Prunus persica Batsch) seedlings. Sci Hort 94:285-295.

Schellenbaum L, Berta G, Ravolanirina F, Tisserant B, Gianinazzi $S$, Fitter AH (1991). Influence of endo-mycorrhizal infection on root morphology in a micro-propagated woody plant species (Vitis vinifera L.). Ann Bot 68:135-141.

Seifert EK, Bever JD, Maron JL (2009). Evidence for the evolution of reduced mycorrhizal dependence during plant invasion. Ecology 90:1055-1062.

Smith SE, Read DJ (2008). Mycorrhizal Symbiosis, $3^{\text {rd }}$ Ed. Academic Press, New York.

Tolsma AD, Read SM, Tolhurst KG (2007). Roots of Australian alpine plant species contain high levels of stored carbohydrates independent of post-fire regeneration strategy. Aust J Bot 55:771-779.

Trotta A, Varese GC, Gnavi E, Fusconi A, Sampo S, Berta G (1996). Interaction between the soil-borne root pathogen Phytophthora nicotianae var. parasitica and the arbuscular mycorrhizal fungus Glomus mosseae in tomato plants. Plant Soil 185:199-209.

Walter A, Nagel KA (2006). Root growth reacts rapidly and more pronounced than shoot growth towards increasing light intensity in tobacco seedlings. Plant Signal Behav 1:225-226.

Wu QS, Zou YN (2009). The effect of dual applicatoin of arbuscular mycorrhizal fungi and polyamines upon growth and nutrient uptake on trifoliate orange (Poncirus trifoliata) seeldings. Not Bot Horti Agrobo 37(2):95-98.

Wu QS, Zou YN, Zhan TT, Liu CY (2010). Polyamines particpate in mycorrhizal and root development of citrus (Citrus tangerine) seedlings. Not Bot Horti Agrobo 38(3):25-31.

Zhang ZL, Zai LJ (2004). Expermental Instructment of Plant Physiology, $3^{\text {rd }}$ Ed. Higher Education Press, Beijing.

Zhu J, Ingram PA, Benfey PN, Elich T (2011). From lab to field, new approaches to phenotyping root system architecture. Curr Opin Plant Biol 14:310-317. 